\title{
Mechanical Properties of Synthetic Fibers at Low Temperature
}

\author{
By Seinosuke Kakiage, Kohji Yamaga and Tetsuyuki Sasai, Members, TMSJ \\ Faculty of Engineering, Gunma University, Kiryu, Gunma-ken
}

Based on Journal of the Textile Machinery Society of Japan, Transactions, Vol.21,Nos.7/8, 177-128-30 (1968)

\begin{abstract}
We have built a low-temperature tensile tester and used it in a test of the tensile stlength, breaking elongation and toughness of synthetic fibers.

The strength and elongation curves of synthetic fibers at a temperature of $-50^{\circ} \mathrm{C} \sim$ $+70^{\circ} \mathrm{C}$ can be expressed by a quadratic curve for strength-temperature and by a nearly straight line for elongation-temperature.

The products of these two equations can be expressed, by a cubic curve, as a function of the work of rupture versus temperature. Generally, they have optimum and minimum values. The cubic equation deduced from these two equations almost coincides with experimental results.

The optimum value of a nylon fiber is obtainable at a temperature of about $-20^{\circ} \mathrm{C}$.

The work of rupture of $70 \mathrm{~d}$ nylon yarn, $15 \mathrm{~cm}$ in gauge length, is expressible by the following equation:

$\mathrm{W}_{2}=9.7 \times 10^{-3} \mathrm{~T}^{3}-7.95 \mathrm{~T}^{2}+2150 \mathrm{~T}-191000$

where $\mathrm{W}_{2}$ : work of rupture $(\mathrm{g} . \mathrm{cm})$

$\mathrm{T}$ : absolute temperature $\left({ }^{\circ} \mathrm{K}\right)$
\end{abstract}

\section{Introduction}

In studying the thermal properties of synthetic fibers, we can understand them more concretely by considering them in relation to a wide range of temperatures. We have measured the properties at temperatures ranging from $-50^{\circ} \mathrm{C}$ to $+70^{\circ} \mathrm{C}$ to study phenomena at low temperature in relation to the properties at high temperature. The low-temperature tensile tester uses the so-called Peltier effect. It is relatively small in size and can be set at any temperature easily.

Generally, synthetic fibers increase in strenghth as the temperature falls, and decrease in elongation as the temperature rises. This is considered the thermal effect on the attractive force of molecular chains, i.e., on the main and secondary valency forces. The latter electrostatic secondary attractive force is believed to influence the tensile strength in inverse ratio to the distance between the molecular chains and the temperature.

Consequently, the relation between the tensile work of rupture and the temperature is not simple, especially because strength increases and elongation decreases as the temperature goes down. We have made our experiment with this fact carefully in mind to investigate the utility value of synthetic fibers.

\section{Experimental Instrument}

The principal part of the experimental instrument is

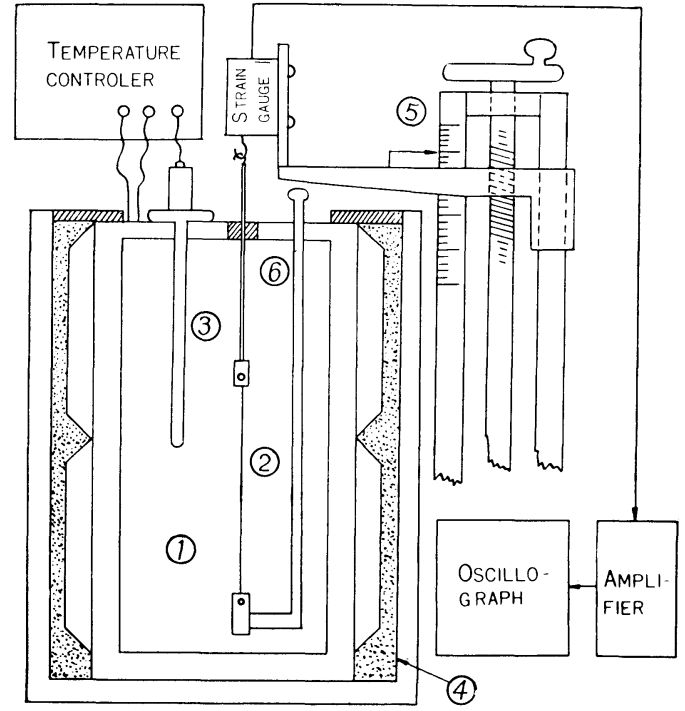

(1) Low-temperature box $(300 \times 115 \times 115 \mathrm{~mm})$

(2) Specimen

(3) Senser of temperature

(4) Freezing mixture (ice or metyle alcohole + dry ice)

(5) Drawing device

(6) Specimen-setting lever

Fig. 1 Schematic view of low temperature experimental apparatus 
shown in Fig. 1. The cooling bath is, as previously mentioned, an electrical cooler using the Peltier effect with ice or freezing mixture.

To s_i a sample at clamps in the cooling bath, pick up the lever (6) upward, and we can set the sample (2) at the outside of the bath. Then put the sample in the bath, turn the handle of the tensile device and measure tensile stress with the strain gauge at the top of the arm of the scale.

\section{Experimental Results}

Commercially sold polyester and nylon yarns, as well as those heat-treated at various temperatures, were used as samples. They were $15 \mathrm{~cm}$ in length.

\section{3-1. Nylon and Polyester Yarns Compared}

The results for the nylon yarn are shown in Fig. 3. The various values were obtained from the stress-strain curve of the nylon yarn on the pen writing oscillogragh. The yarn increased in strength with a decline in temperature, making a concave, upward curve. The yarn decreased in elongation proportionally to a drop in temperature. The dotted line shows the results for moisture-free specimens treated with phosohorus pentoxide $\left(\mathrm{P}_{2} \mathrm{O}_{5}\right)$ and daubed with silicon oil to keep them from absorbing moisture in the atmosphere. The treated yarns all showed lower values than the untreated ones. The results for polyester(Tetoron) yarn resemble these for nylon yarn.

The work of rupture is shown in Fig. 5 as a toughness expressible by the weight $(\mathrm{mg})$ of the chart on which stressstrain curves are written. The paper is a clipping from the drawing of the stress-strain curve of the yarn.

Nylon and Tetoron decrease slightly in toughness with a decline in temperature, increase at a temperature of about $\mathrm{O}^{\circ} \mathrm{C}$, and decrease again abruptly at low temperature. They have optimum values at a temperature of about $-20^{\circ} \mathrm{C}$.

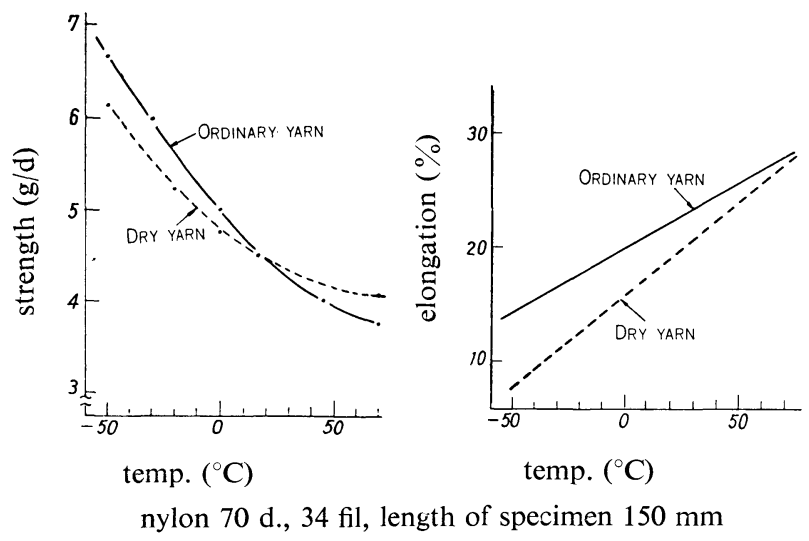

Fig. 3 Relation between strength-elongation and temperature of nylon yarn

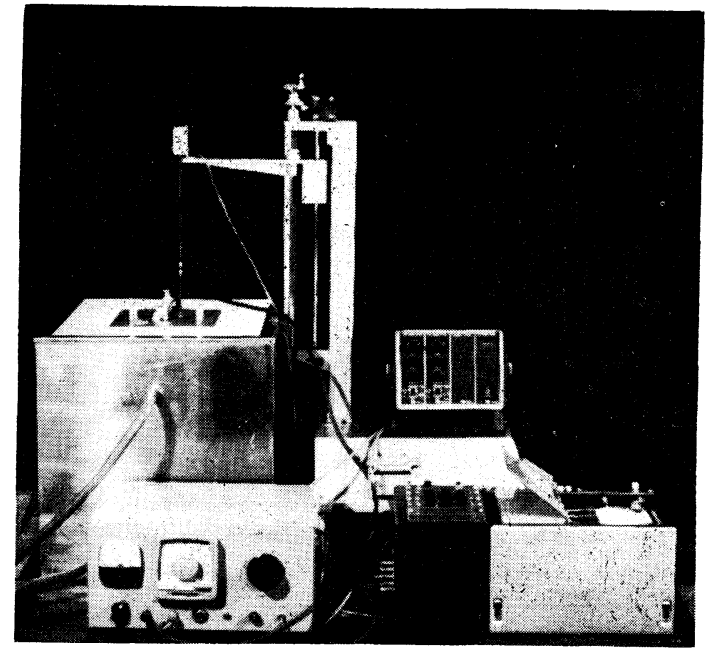

Fig. 2 Low-temperature experimental apparutus

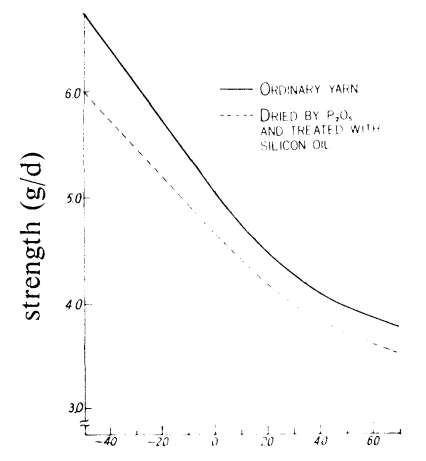

temp. $\left({ }^{\circ} \mathrm{C}\right)$

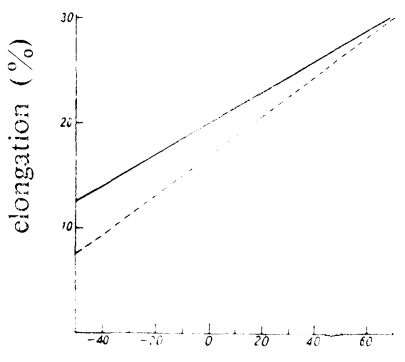

temp. $\left({ }^{\circ} \mathrm{C}\right)$ polyester 75 d. 36 fil.

Fig. 4 Relation between strength-elongation and temperature of polyester yarn

Dry nylon tends to decrease drastically in toughness below a temperature of $-20^{\circ} \mathrm{C}$.

3-2. Experiments with Nylon Yarns Differing in Draft Ratio and Heat-treated at Various Temperatures.

Our experiments covered 5 draft ratios: $-20,-10,-5$, 0 , and $+5(\%)$. The prefix - denotes extension of yarn; + , contraction. The specimens were heat-treated in air temperatures of $160^{\circ} \mathrm{C}, 180^{\circ} \mathrm{C}$ and $200^{\circ} \mathrm{C}$ with a nontouch, radiation heater. The heater being $60 \mathrm{~cm}$ long and yarn velocity $30 \mathrm{~m} / \mathrm{min}$, the time required for a yarn to pass through the heater was 1.2 seconds. The yarn deniers were measured as shown in Fig. 6 to ascertain the degree of heat-setting as a basic datum. The deniers of drafted yarns after boiling in hot water for about 10 minutes are shown by the dotted lines as a matter of information. 


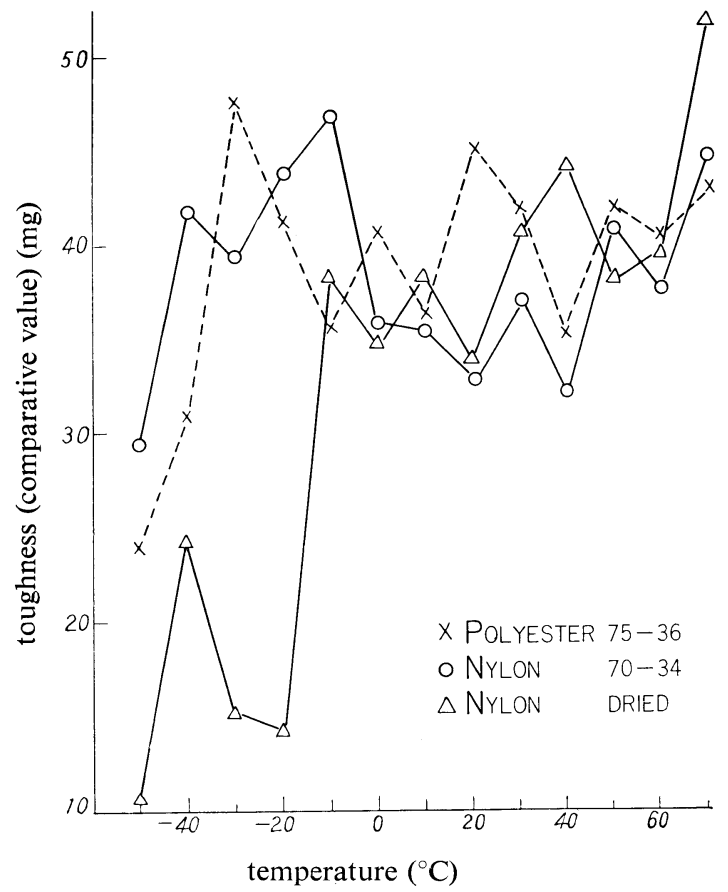

Fig. 5 Relation between temperature and toughness

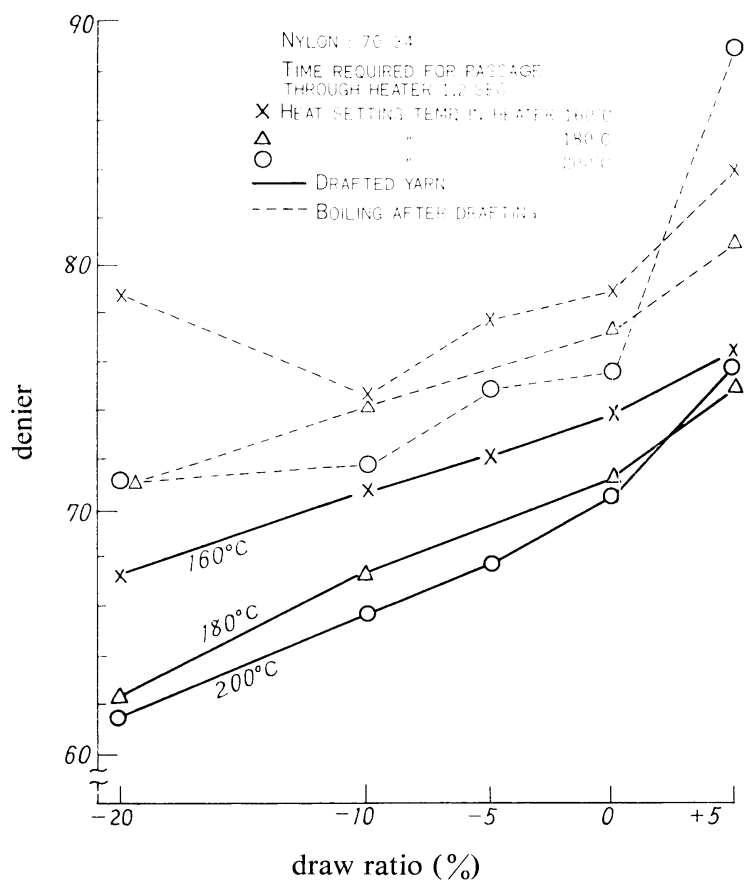

Fig. 6 Draw ratio and denier

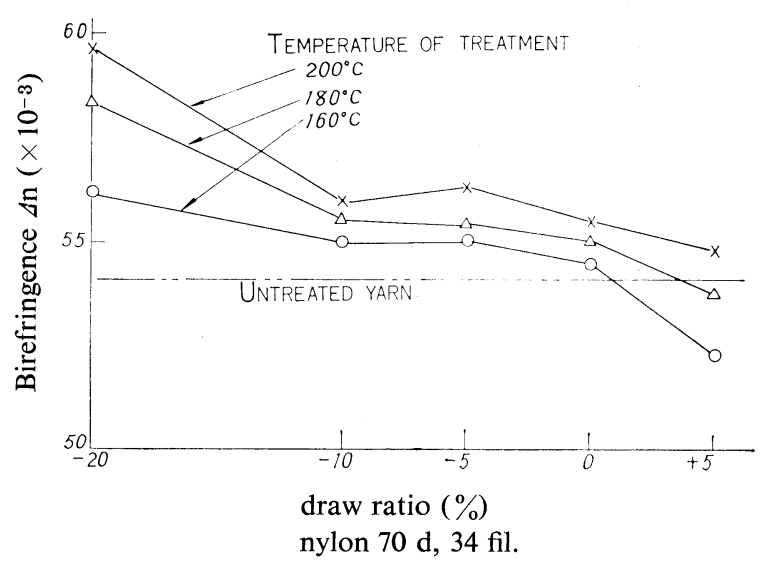

Fig. 7 Relation between bierfringence and draw ratio

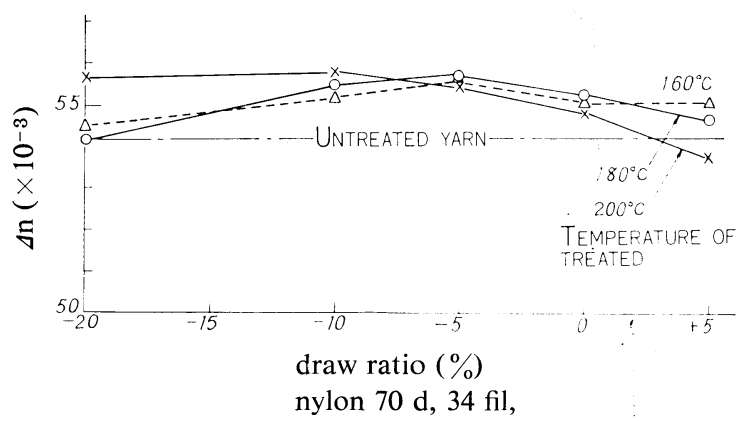

Fig. 8 Birefringence (after treated and boiled in water)

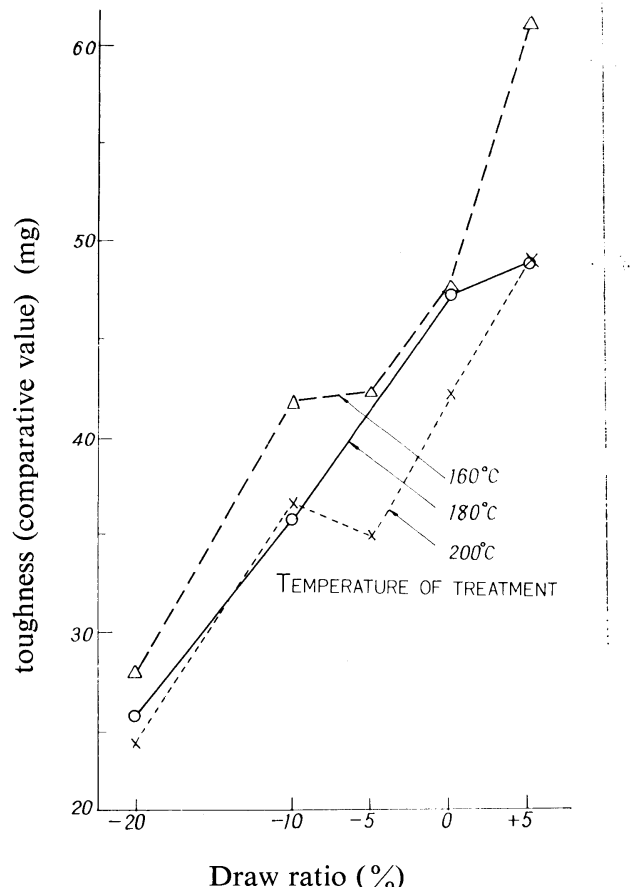

nylon $70 \mathrm{~d}, 34 \mathrm{fil}$, speed of tester $5 \mathrm{~cm} / \mathrm{min}$.

Temperature of box $20^{\circ} \mathrm{C}$

Fig. 9.a Relation between drawing-heat treating and toughness of nylon 


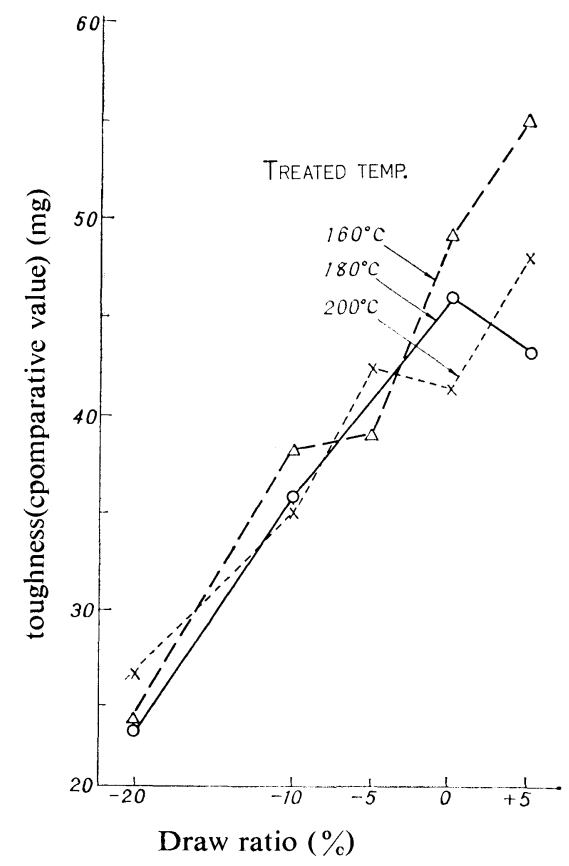

Fig. 9.b Temperature of box: $1{ }^{\circ} \mathrm{C}$

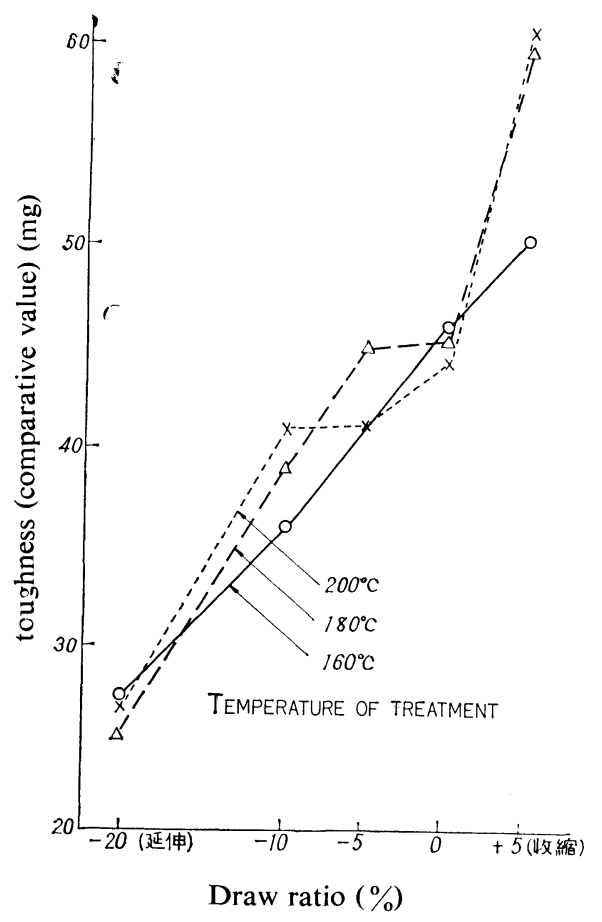

Fig. 9.c Temperature of box, $-10^{\circ} \mathrm{C}$

The values of birefringence of the specimens are given in Fig. 7. The higher the temperature of heat-setting, the higher the value of birefringence of the yarn. For, the higher the draft ratio, the smaller the yarn denier. Fig. 8 shows the values of birefringence of the yarns boiled in hot water.

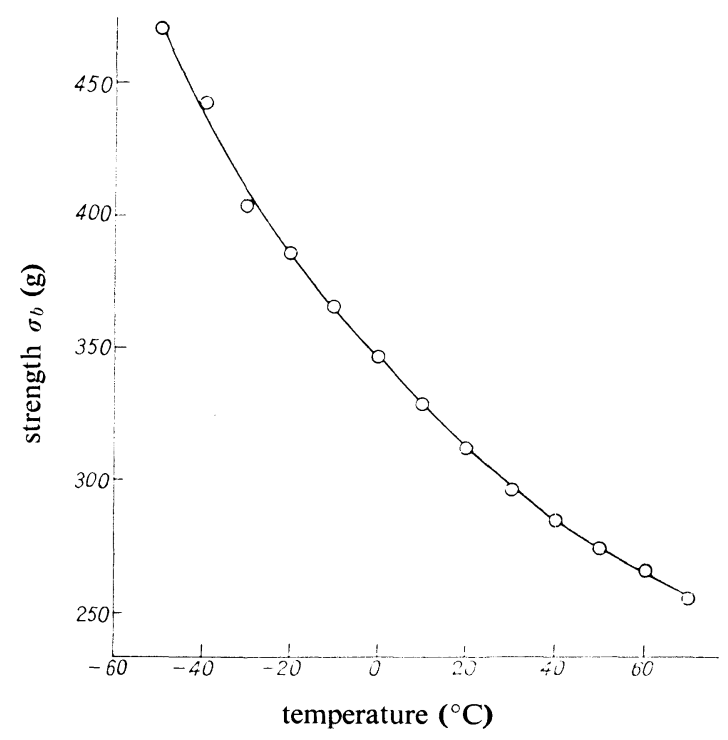

Fig. 10 Strength-temperature curve of nylon yarn (70d, 34 fil,)

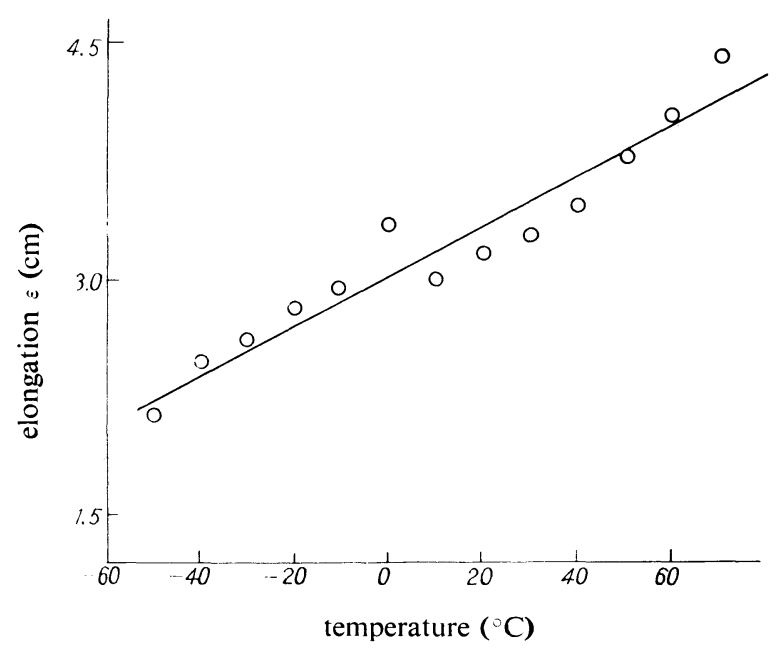

Fig. 11 Elongation-temperature curve of nylon yarn (70d, 34 fil.)

Specimen drafted at $-20 \%$ extension is far beyond the yield point of their stress-strain curve. This may be thought of as the collapse of the inner structure of some parts of the yarns. This fact goes to show that the yarns received the expected effects from heat-setting.

Figs. $9 \mathrm{a}-\mathrm{c}$ show the value of toughness measured by the same method from the stress-strain curve of the yarns. Proportional relations are generally observed between an increase in the draft ratio and a decrease in toughness. The degree of toughness is high if the temperature of heatsetting is low-and vice versa.

\section{Discussion}

Figs. 10 and 11 are strength and elongation curves for temperatures of $-50^{\circ} \mathrm{C} \sim+70^{\circ} \mathrm{C}$ and are the same as in 
Fig. 3. The unit of vertical axis of Fig. 12 is shown, for the sake of convenience, with $\mathrm{g}-\mathrm{cm}$ to designate the work of rupture $(\mathrm{g}-\mathrm{cm})$ directly.

We can get experimental formulas from the plots of Figs. 10 and 11. They are, respectively, a quadratic curved line and a linear line and are expressible as follows:

$$
\sigma_{b}=0.01 \mathrm{~T}^{2}-7.43 \mathrm{~T}+1631.1
$$

and

$$
\varepsilon=0.016 \mathrm{~T}-1.368
$$

where $\sigma_{b}$ is strength $(\mathrm{g}), \approx$ is elongation $(\mathrm{cm})$ and $\mathrm{T}$ is absolute temperature $\left({ }^{\circ} \mathrm{K}\right)$.

Multiplying eq. (1) by eq. (2), we obtain the following expression:

$$
\mathrm{W}_{1}=1.6 \times 10^{-4} \mathrm{~T}^{3}-0.133 \mathrm{~T}^{2}+0.469 \mathrm{~T}-1670 \ldots \text { (3) }
$$

The relation between the values of $W_{1}$ and the temperature is shown by the curved line in Fig. 12.

$\mathrm{W}_{1}$ in eq.(3) is the product of both the base (elongation: $\mathrm{cm}$ ) and the height (strength: $\mathrm{g}$ ) of the stress-strain curve and corresponds to the area of the rectangle. It is proportional to the real work of rupture, that is, the area enclosed in the stress-strain curve.

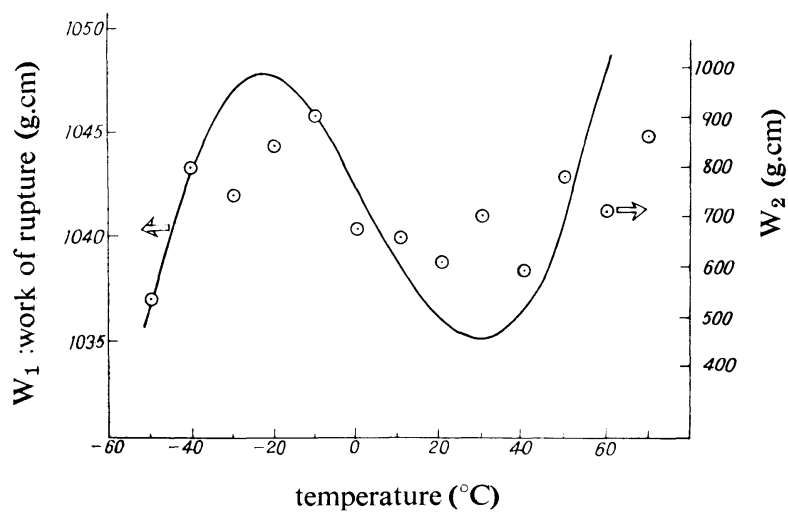

Fig. 12 Relation between work of rupture and temperature

The plots of Fig. 12 denote the work of rupture for temperatures of $-50^{\circ} \mathrm{C} \sim+70^{\circ} \mathrm{C}$. The work of rupture is toughness estimated from the curves on the charts. On comparing these experimental values with eq.(3), we find about the same tendency optimum and minimum points in temperature as calculated one.
Fitting the unit of eq.(3) to the unit of right-hand scale leads to obtain eq.(4):

$$
\mathrm{W}_{2}=9.7 \times 10^{-3} \mathrm{~T}^{3}-7.95 \mathrm{~T}^{2}+2150 \mathrm{~T}-191000 . .(4)
$$

thus showing that the relation between eqs.(3) and (4) is:

$$
\mathrm{W}_{2} \fallingdotseq 51.1 \mathrm{~W}_{1}-106000
$$

$\mathrm{W}_{2}$, the tensile work of rupture of nylon fibers (79d, 34fil.), being the cubic expression shown in eq.(4) for temperatures of $-50^{\circ} \mathrm{C} \sim+70^{\circ} \mathrm{C}$.

The relation between $W_{1}$ and $W_{2}$, expressed as the product of strength and elongation, is given in eq.(5).

The optimum and minimum values in Fig .12 undergo minute changes as the inclination and curvature of the curve of Fig. 10 change. They sometimes show up distinctly and sometimes indistinctly.

A few papers are written about the low temperature in reference to the wide range like this on the mechanical properties of fibers, and their results ${ }^{[1 \cdot 2]}$ are linear in narrow range refered to in Figs. 10 and 11. In these cases, the product of two linear equations makes a convex parabola and has a maximum value in the center.

The tensile work of rupture of fibers is related to important problems in the end use of fabrics in frigid zones. At low temperature, fibers increase in strength but decrease in elongation and break easily.

A tearing test is more practical than a tensile test. A tearing test shows results which include elongation data. The relation between the results obtained from our experiments under review and a tearing test will be detailed at a later day.

\section{Conclusions}

1. Tensile tests of synthetic fibers at low temperature have shown that the work of rupture gives a cubic curve if the temperature is $-50^{\circ} \mathrm{C}$ to $+70^{\circ} \mathrm{C}$. The optimum rupture energy has near $-20^{\circ} \mathrm{C}$ and drops abruptly below $-50^{\circ} \mathrm{C}$.

2. These results seem to have an important meaning to the work of rupture of clothings and textile fibers used for industrial purposes in the frigid zone. Particularly in case of below $-50^{\circ} \mathrm{C}$, an attention should be taken to their practical end-uses. These mechanical properties can afford to be improved by a method to well-combine the drawing, heat treatment, etc.

\section{References}

[1] B. Farrow; J.Text.Inst., 47, T58(1956)

[2] B. Farrow; J.Text.Inst., 47, T650(1956) 